\title{
Oda a la ambigüedad Crónica
}

\section{Susana Chávez-Silverman, Pomona College}

\author{
Claramonte, Califas
}

11-II-06

Para P.A. $y$ Para D.W.F.

Pensé, por un momento eterno, que me habías perdido, que te había perdido. That we'd lost each other.

¿Cuánto tiempo without words, without even a glimpse? How could we go that long without?

Después de ese torrential exchange que sólo ahora me vengo a dar plena cuenta you rely upon like nourishment. Me lo dices en tu carta, pero antes, en otra carta, once upon a time, repudiaste, as excessive. Discomfiting.

Waves of alivio wash over me, ahora que nos hemos permitido honrar, decir las palabras vedadas. Pronunciamos palabras como amor, miedo, daring, souls alike. Bueno, en realidad, souls bien different, pero touching. We tread, gingerly, por territorios no cartografiados. 
Te permites (some dam broke in you — un límite traspasado — el otro día, and I am grateful), you allow yourself the luxury of recognising love. Sencillamente esto: sin acusarlo de desviarte. Aun en esta, una forma antes desconocida. Unrecognized.

Camino rápido por esta sudden, too-early primavera. A small, icy rivulet of sweat runs down my spine. My tissue-weight turquoise cotton top se me pega, cual ventosa, a la piel, semi-transparentándose. My lips part slightly; tiny casi jadeos se me escapan. Voy rápido, long-limbed. Y hace un calor intenso, unnatural en este supposedly still invernal Aquarius birthday season.

Un atroz Rottweiler, slightly overweight, compact and dense as a rhino, me aborda, pegado a su equally-chunky dueño. Me recuerda (me hace acordar, as they say en Buenos Aires), por un momento, el film “Doggy Love” con Gael García Bernal. Toda esa flashy, desperate, gritty mexicanidad. I watched it voluptuously, yearningly en ese cine en Buenos Aires. Missing, visceralmente, the smells, the sounds of home. De mi otro hogar.

Pero really, apenas veo al Rottweiler, de reojo. Camino tan rápido, casi estoy corriendo. And besides, you know me: mucho más mío es el olfato.

Blooming antes de tiempo, a deshora, las fuzzy mimosa blossoms despiden su pale, dusty yellow perfume. Me saltan las lágrimas de repente, unbidden, casi inappropriate, even, on this blindingly hot, gorgeous mid-winter day: how long since I've been home?

Marcos y Sara me platicaron el otro día de Santa Cruz, and they may as well have been talking about Mars. Ya no está mami, my last link to home. No es mío, ya no es mi lugar en el mundo.

Pero the mimosa branches used to cool my lazy afternoon walks, de vuelta a casa de la high school. Whoosh, whoosh. Soplaban en la brisa marítima. The eucalyptus scattered their pods; occasionally a seagull would venture the quarter mile inland, y graznaba 
overhead mientras yo volvía a casa, avoiding scary huge dogs, componiendo poemas en la cabeza.

Camino, ahora. I reach up, overhead, and crush tiny red pirul berries. El Paulie cree que son native to Australia. Yeah right, as if! OB-vio, son una introduced species. Bueno, I might've thought they were nativos a Califas, si no los hubiese visto, originally, en México. Ahora agarro una rama frondosa de delgadas, pálidas hojas. I rub them between my fingers — oh, la pimentosa oscura fragancia—y estoy en Zapopan, en verano.

La última vez que estuve en Guadalajara, con el “Noviete” Foster, fuimos en taxi y él platicándome de Pizarnik y sus amores. Y nomás circulamos por donde era, donde había sido mi barrio, y yo llorando por todo lo que se había ido. For everything I'd lost, por todo lo que ya no era.

No puedo seguir así, rememorando. Tendré que llorar; it's going to slow me down, y necesito sudar, extenuarme, para volver a casa apacible, focused, para escribir.

Pero estos olores son too much. No puedo no estar en otros lugares, (mis) otros lugares. Tan faraway, tan míos, en mí, still. Siempre.

One of those places is (with) you.

Ecologically speaking (y LITTLE EYE, lo soy: reciclo, hasta compro scratchy kleenex y todo), este definite sign of global warming, este premature heat, debería tenerme alarmada, en el infierno. Y me choca el calor anygüey; tú lo sabes. Sufro, quiero estar sólo adentro, moss green home-made velvet curtains drawn, fingiendo ser vampiresa. Escribiendo. 
Pero speaking from the heart-y antes de que comience el true, searing, Imperio del

Interior summer blast furnace, allí por agosto, septiembre-right here, right now estoy en el cielo.

Y ¿sabes que? Allí me quedo, un ratito. 